\title{
Roots or Edges? \\ Explaining variation in children's early verb forms across five Mayan languages
}

\section{Clifton Pye, Barbara Pfeiler, Lourdes de León, Penelope Brown and Pedro Mateo*}

\section{Introduction}

Children learning K'iche', Tzeltal, Tzotzil, Q'anjob'al and Yukatek produce different forms of their first verbs (Brown 1997, 1998; de León 1999a; Mateo 2005; Pfeiler \& Martín Briceño 1998; Pye 1983). Children acquiring Tzeltal and Tzotzil initially produce a high proportion of bare verb roots, while children learning K'iche', Q'anjob'al and Yukatek produce many more combinations of a verb root plus suffix. Brown (1997: 45) found that the first 35 verbs produced by one Tzeltal boy were all bare roots. A Tzeltal girl produced a greater variety of verb forms, but bare roots still constitute over seventy percent of her first 35 verb forms. De León (1999a, 1999b) documents similar early use of verb roots by children learning Tzotzil. In contrast, Pye (1983: 592) showed that children learning K'iche' at a comparable age preferred verb forms containing a suffix over bare roots by better than a four to one ratio. Our basic research question in this paper is this: what motivates Mayan children's production of bare verb roots? We use the term 'edge' to refer to the beginning or end of a verb. The verb root may appear at the right edge of the verb if there are no suffixes, and at the left edge of the verb if there are no prefixes (1). Our goal is to examine the degree to which common factors in the input influence children's production of bare verb forms across a set of five Mayan languages.

(1) Roots and Edges in Mayan Verbs

$\begin{array}{ccc}\text { Prefix }+[\text { Root }]+\text { Derivation }+ \text { Suffix } \\ \text { Left } & \text { Left Right } & \text { Right } \\ \text { word } & \text { Root } & \text { word } \\ \text { edge } & \text { edges } & \text { edge }\end{array}$


Children's verb forms have assumed a significant theoretical importance in recent years since the introduction of the Root Infinitive Hypothesis (Wexler 1994), which claims that children optionally use non-finite verb forms in simple clauses. Constructionist theorists, on the other hand, claim that the form of children's verbs reflects structural features of the adult language (Tomasello 2003). Data from the Mayan languages are ideally suited to resolving this debate as the languages feature a rich system of verbal inflection with separate clitics or affixes for aspect, subject, object and transitivity.

In the following section, we first introduce the structure of verbs in the adult languages and discuss the morphemes that occur on the left and right edges of Mayan verbs. We next discuss the verb forms that children produced in five Mayan languages. We then proceed to test nine different left edge and right edge structural features in the adult language that could account for the children's production of bare verb forms. We end with a summary of our findings and a discussion of the implications the findings have for language acquisition theories.

\section{Mayan Verbal Inflection}

Verbs in Mayan languages have a predominantly agglutinative morphology. The canonical root form of verbs is CVC. Mayan languages are verbinitial, head marked languages with separate agreement inflections for the subject and object on transitive verbs. Mayan verbs are also inflected for aspect and mood. In addition, the verbs carry what Terrence Kaufman (1990) labels a 'status suffix'. The status suffix differs considerably across the Mayan languages, but generally marks verb transitivity and mood. A general morphological template for the Mayan languages is shown in (2). The absolutive comes after the aspectual prefix in K'iche' and Q'anjob'al $(\text { Absolutive })_{1}$ ), and after the status suffix in Tzeltal and Yukatek (Absolutive $_{2}$ ). It is found in both positions in Tzotzil.

(2) Mayan transitive verb templatel fn abbreviation conventions ${ }^{1}$ Aspect + Absolutive $_{1}+$ Ergative + Verb_Stem + Status + Absolutive $_{2}$ K'iche': k-at-k-il-o + Plural

INC-2ABS-3ERG.PL-SEe-STA TV-INC $_{\text {Th }}$

'They see you'

Yukatek: k-uy il-ik-eč-o'ob'

INC-3ERG See-STA ${ }_{\text {TV-INC }}-2$ ABS-PL

'They see you' 
Mayan languages use a set of ergative cross-reference prefixes to mark the subjects of transitive verbs and absolutive cross-reference affixes to mark both the subjects of intransitive verbs and the objects of transitive verbs (3). The absolutive markers are prefixes in Q'anjob'al and K'iche', and suffixes in Yukatek and Tzeltal. Tzotzil has absolutive prefixes and suffixes. The third person absolutive marker is a zero morpheme in these five Mayan languages, which provides a context in which the verb root might occur on the right or left edge of the verb. Q'anjob'al and Yukatek extend ergative markers to the subjects of intransitive verbs in specific contexts.

\section{(3)}

Ergative Agreement

Subject of transitive verbs

Nominal possessors

\section{Absolutive Agreement}

Subject of intransitive verbs

Object of transitive verbs

\section{Left Edge Contexts}

Aspect marking differs considerably across the Mayan languages and affects the contexts in which the verb roots appear at the left edge of the verb word. These differences are evident in the aspectual paradigms shown in (4). This variation occurs in both the range of obligatory contexts for aspectual prefixes as well as the degree of fusion between the verbal complex and the verbal prefixes. K'iche' is clearly different from the other languages in requiring an overt prefix for positive imperatives. Negative imperatives (e.g., 'don't hit your sister') all have a marker for negation that precedes the verb in our languages. Tzotzil has distinct incompletive and completive aspectual prefixes for transitive and intransitive verbs as well as for person. First and third person transitive verbs in Tzotzil have the incompletive prefix $t a-$, while second person incompletive transitive verbs have the prefix $c h$.

Mayan Aspect Paradigms ${ }^{2}$

\begin{tabular}{|c|c|c|c|c|c|c|}
\hline & \multirow{2}{*}{$\begin{array}{l}\text { Yukatek } \\
\text { TV IV }\end{array}$} & Tzeltal & \multicolumn{2}{|c|}{ Tzotzil } & Q'anjob'al & K'iche' \\
\hline & & TV IV & TV & IV & TV IV & TV IV \\
\hline INC & $k-\quad k-$ & ya ya $x-$ & $\mathrm{ta}-(1,3) \mathrm{ch}-(2)$ & $\mathrm{ch}-(1,2)$ ta-(3) & ch- & $k-$ \\
\hline COM & $h / 0$ & la $g$ & $\mathrm{i}-(1,3) \emptyset(2)$ & $1-(1,2) \mathrm{i}-(3)$ & $\max -\max -$ & $x-$ \\
\hline IMP & $\emptyset$ & $\emptyset$ & o & 0 & $\emptyset \quad 0$ & ch-/k- ch-/k- \\
\hline $\begin{array}{l}\text { SUBJ } \\
\text { POT }\end{array}$ & káa/sáan & $\emptyset$ & $\emptyset$ & 0 & $\begin{array}{c}\emptyset \\
\text { hoq } \\
\text { hoq }\end{array}$ & $\begin{array}{c}\operatorname{ch}-/ \mathrm{k}-\operatorname{ch}-/ \mathrm{k}- \\
\mathrm{k}-\mathrm{k}-\end{array}$ \\
\hline
\end{tabular}


K'iche' adults use an imperative prefix as well as the regular agreement prefix for second person in their imperatives, both positive and negative. However, K'iche' child directed speech contains some examples where the adults omit the prefixes in imperatives. The negative imperatives in the other languages retain the PM imperative system with agreement markers and even aspectual prefixes. Tzotzil does not mark completive aspect on transitive verbs with second person subjects. When an adverb follows the verb, Tzotzil permits the omission of the completive aspect prefix for third person intransitive verbs so the verb root occurs at the left word edge in this context. Yukatek, Tzeltal, Tzotzil and Q'anjob'al allow adverbs to occur between the aspect markers and the verb roots, hence the aspect markers have a different morphological status in these languages. The following example for Q'anjob'al shows a transitive verb with an adverb. In this dialect the third person ergative marking for consonant-initial verbs is zero. In this example, the transitive verb is a complement of an auxiliary verb, and in the third person the verb root can occur at the left verb edge. The Yukatek example shows a case where an adverb is inserted between the ergative subject marker and the verb root. In this case, the verb root does not appear at the left word edge because of the overt ergative subject marking.

(5) Adverb Particles

a. Q'anjob'al

max-ach wal $\emptyset$-tayne-j

COM-2ABS INTENS 3ERG-look_after-STA TV-DER $_{\text {- }}$

'He/she really looked_after you.'

b. Yukatek

$\mathrm{k}$-in hach il-ik

INC-1 ERG INTENS SEe-STA TV-INC $_{\text {Th }}$

'I am focussing on $\mathrm{him} / \mathrm{her} / \mathrm{it}$.'

Q'anjob'al allows intransitive complements of the progressive to occur with the verb root at the left word edge.

Table 1 lists the contexts for our languages in which the verb root can occur at the left word edge. Note that we distinguish between transitive and intransitive verbs since the contexts where the verb root can occur at the left word edge differ by the transitivity of the verb. 
Table 1. Left Word Edge Contexts

\begin{tabular}{lll}
\hline Language & Transitivity & Left Word Edge Contexts \\
\hline Yukatek & $\begin{array}{l}\text { Intransitive Verb } \\
\text { Transitive Verb }\end{array}$ & $\begin{array}{l}\text { Positive Imperative; COM 1-6 } \\
\text { Positive Imperative }\end{array}$ \\
\hline Tzeltal & $\begin{array}{l}\text { Intransitive Verb } \\
\text { Transitive Verb }\end{array}$ & $\begin{array}{l}\text { Positive Imperative; COM 1-6 } \\
\text { Positive Imperative }\end{array}$ \\
\hline Tzotzil & Intransitive Verb & Positive Imperative; (COM 3 and 6) \\
& Transitive Verb & Positive Imperative \\
\hline Q'anjob'al & Intransitive Verb & Positive Imperative; IV verb complement \\
& Transitive Verb & Positive Imperative; IV verb complement \\
\hline K'iche' & Intransitive Verb & Imperative (suppletive forms) \\
\hline
\end{tabular}

Table 1 shows the necessity of distinguishing between transitive and intransitive verbs for the purpose of analyzing the contexts in which the verb root may appear at the left word edge. We provide examples of verb roots at the left word edge in (6).

(6) Examples of Left Word Edge Contexts

Yukatek - IV com2

(h) lúub-ech

(COM) fall-2ABS

'You fell.'

Tzeltal - Positive Imperative

jajch-an

get_up-STA $\mathrm{S}_{\mathrm{lv}-\mathrm{MMP}}$

'Get up!'

Tzotzil - IV

(i)- 0 -bat xa

(COM)-3ABS-go now

'She's gone now.'

Q'anjob'al - IVverb complement

q-Ø-xew Ø-qajab'-i

POT-3ABS-finish 3ERG-talk-STA ${ }_{\mathrm{IV}-\mathrm{NN} \text {. }}$

'When he/she finishes talking.' 
K'iche' - Suppletive Imperative

saj

come

'Come!'

\section{Right Edge Contexts}

The status suffixes occur to the right of the verb root in Mayan languages, however they exhibit considerable formal variation across the languages as shown in (7). Tzeltal and Tzotzil lost the ProtoMayan (PM) status suffixes for verbs in the incompletive and completive aspects (Kaufman \& Norman 1984), while Yukatek has two forms of status suffixes for the two classes of intransitive verbs. The Q'anjob'al and K'iche' 'plain' status suffixes vary in form according to whether the verb occurs at the end of the sentence. The forms shown in parentheses only appear when the verb is in sentence final position. K'iche' and Q'anjob'al have a separate class of status suffixes that appear on derived transitive verbs in all sentence positions.

Mayan status paradigms

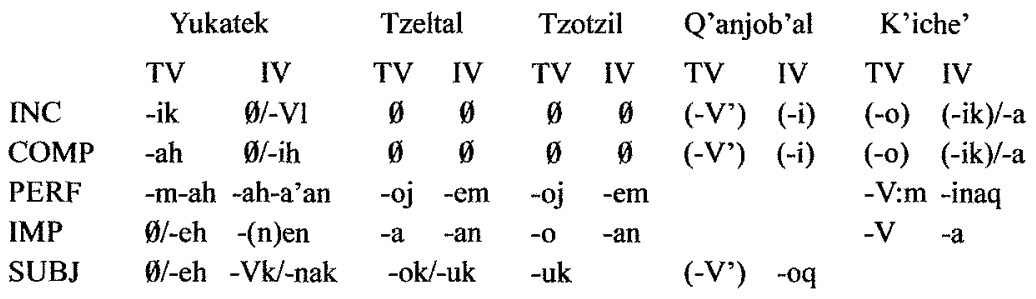

In Yukatek all the status suffixes appear when the verb occurs at the end of the sentence. The status suffixes also appear on transitive verbs in sentence-medial position when the verb is in the incompletive and completive aspects. In verbs in the completive aspect, an optional phonological contraction process deletes the status suffix (8).

\section{Yukatek Contraction}

a. Before contraction

t-a mach-ah le che' $=0$ '

COM-2ERG grab-STA TV-COM $_{\text {DET wood=DIST }}$

'You grabbed this stick.' 
b. After contraction

t-a mache che' $^{\prime}=\mathbf{o}^{\prime}$

COM-2ERG grab=DET wood=DIST

'You grabbed this stick.'

Mayan languages commonly employ contraction processes at the surface phonetic level. We defined the "right edge" of the word at the syntactic level before such elisions occur. The verb root in the first Yukatek example (8a) was not counted as occurring at the right edge since it contains a status suffix while the verb in $8 b$ does not have an overt status suffix, but at the morpho-syntactic level it does (i.e. before the contraction $-\mathrm{ah}+\mathrm{le}>\mathrm{e}$ ) and so was not counted as a case where the root occurs at the right edge.

Several other details must be recognized. The position of absolutive marking on the verb also interacts with the use of a status suffix. The absolutive is a prefix in K'iche' and Q'anjob'al, but a suffix in Tzeltal and Yukatek. Consequently, the completive status suffix for intransitive verbs in Yukatek only occurs for third person absolutive subjects that have a zero form. The imperative status suffix for transitive verbs in Tzeltal and Tzotzil also fails to surface when the verb has the applicative suffix $-b e$.

Table 2 lists the contexts in which the verb root can surface without an overt suffix - i.e. at the right edge of the word - in our five languages.

Table 2. Right Word Edge Contexts

\begin{tabular}{|c|c|c|}
\hline Language & Transitivity & Right Word Edge Contexts \\
\hline Yukatek & $\begin{array}{l}\text { Intransitive Active Verb } \\
\text { Transitive Verb }\end{array}$ & $\begin{array}{l}\mathrm{INC1}-3 \\
\mathrm{IMP}_{\mathrm{SM}}\end{array}$ \\
\hline Tzeltal & $\begin{array}{l}\text { Intransitive Verb } \\
\text { Transitive Verb }\end{array}$ & $\begin{array}{l}\text { INC3; COM3; } \\
\text { INC3; COM3; IMP }\end{array}$ \\
\hline Tzotzil & $\begin{array}{l}\text { Intransitive Verb } \\
\text { Transitive Verb }\end{array}$ & $\begin{array}{l}\text { INC1-3; COM1-3; IMP } \\
\text { INCIEG }-3 ; \mathrm{COM} 1-3 ; \mathrm{IMP}_{\mathrm{NEG}}\end{array}$ \\
\hline Q'anjob'al & $\begin{array}{l}\text { Intransitive Verb } \\
\text { Transitive Verb }\end{array}$ & $\begin{array}{l}\text { INC1-3 }{ }_{S M} ; \text { COM } 1-3_{S M} ; \text { POT } 1-3_{S M} \\
\text { INC } 1-3_{S M} ; \text { COM } 1-3_{S M} ; \text { POT } 1-3_{S M}\end{array}$ \\
\hline K'iche' & $\begin{array}{l}\text { Intransitive Verb } \\
\text { Transitive Verb }\end{array}$ & $\begin{array}{l}\text { INC1-3 } 3 \text { SM COM } 1-3_{S M} \\
\text { INC1-3 } 3 \text { SM COM } 1-3_{S M}\end{array}$ \\
\hline
\end{tabular}

This table specifies distinct contexts for transitive and intransitive verbs, since verb transitivity changes the contexts where the verb root can occur at 
the right edge of the verb word in some of the languages. Yukatek adds a further restriction in the form of the 'active' intransitive verbs. Table 2 only includes nonderived verbs since most derivation adds a suffix to the right edge of all verb stems in all of the languages. The verb root can occur at the right edge of the verb word in the incompletive and completive aspects in all of the languages. However, there is a restriction to third person contexts for transitive verbs in sentence-medial position in Yukatek where the absolutive cross-reference morpheme for the object is zero (9a). Yukatek, Q'anjob'al and K'iche' further restrict the verbs to cases where the verb occurs in sentence-medial position ( $9 b$ and $c$ ). There are a set of more varied contexts shown in the final column of Table 2 . Tzotzil and Tzeltal have an irrealis verb form in which the root can occur at the right edge of the verb word (9d). This is also the case for the potential in Q'anjob'al (9e). Once again, we highlight the verb root in each example in italics.

(9) Examples of Right Word Edge Contexts

a. Yukatek - TV

Taas] u=láak' silla.

bring:IMP 3ERG=other chair.

'Bring another chair!'

b. Yukatek - IVactive

táan in=meyah] k'iiwik]

PROG 1ERG-work] in the plaza

'I'm working in the plaza.'

c. K'iche'

$\mathrm{x}$-in-pet]

iwir]

COM-1 ABS-come] yesterday]

'I came yesterday.'

d. Tzotzil

mu X-a-pik- $\emptyset]$

li vaj=e]

NEG INC-2ERG-touch-3ABS] DET tortilla $=\mathrm{PT}_{\mathrm{DET}}$ ]

'Don't touch the tortilla.'

e. Q'anjob'al

hoq- $\left[\right.$ hin-t $\left.x^{\prime} a j\right]$ an q'apej]

POT-3ABS 1ERG-wash] CL clothes]

'I will wash the clothes.' 


\section{Sentence Edge Contexts}

Tzeltal and Tzotzil lack status suffixes in the incompletive and completive aspects, so in these languages, the verb root can appear simultaneously at the right edge of the verb stem and the right edge of the sentence. We refer to verb roots at the right edge of the verb as occurring at the right word edge. We refer to the condition when the verb root occurs at the end of the sentence as occurring at the right syntactic edge. Verb roots can only occur at the right syntactic edge if they are already at the right word edge. By distinguishing between the word and syntactic contexts we can determine the degree to which children's verb forms reflect features of the lexical and/or syntactic environment of the input language. Q'anjob'al and K'iche', and to a lesser extent Yukatek, have status suffixes that appear at the right sentence edge, so in these three languages, the verb root only occurs at the right edge of the verb stem but not at the end of the sentence. By distinguishing between medial and final contexts across each language, we can assess the degree to which the structurally licensed use of the verb root at the right edge of the verb or at the right edge of the sentence contributes to the children's productions of bare verb roots.

Mayan verb roots also appear at left sentence edges when the sentence begins with a verb that lacks any morphology to the left of the root. This commonly occurs in positive imperative sentences.

This review of Mayan morphology suggests various factors that determine when a Mayan verb root appears at the left or right edge of the verb word in the adult language. We divide these factors into left edge and right edge factors. The left edge factors are: 1 . overt aspect prefixes, and 2. overt cross-referencing prefixes. The right edge factors are: 1 . overt derivational suffixes, 2. overt status suffixes, 3. overt absolutive and plural suffixes, and 4. whether the verb appears in sentence final position.

We have divided what follows into four sections. The next section presents the data we used in our study. The third section presents our tests of the effects of the left edge and right edge factors on the children's production of bare verb forms. The final section discusses the implications of our findings for current theories of verb development in child language.

\section{Subjects \& Data}

Our data is drawn from corpora of naturally occurring speech in family contexts for each of the five languages. ${ }^{3}$ For this study we extracted data on 
verb production from a single child for each language. We used samples with two-year-old children at the one- to two-word stage. The following table provides information on the children's age, and number of sentences for each language.

Table 3. Age, number of sentences, and number of verbs for the child language samples

\begin{tabular}{lcccc}
\hline & Child & Child's Age & No. of Sentences & No. of Verbs \\
\hline Yukatek & ARM & $2 ; 0$ & 265 & 71 \\
Tzeltal & XAN & $2 ; 2$ & 557 & 176 \\
Tzotzil & MAL & $2 ; 2$ & 270 & 47 \\
Q'anjob'al & NIK & $2 ; 3$ & 772 & 29 \\
K'iche' & TIY & $2 ; 1$ & 157 & 37 \\
\hline
\end{tabular}

We tested the verb realization factors by analyzing samples of child directed speech in each language on the assumption that child directed speech would reflect the structural constraints in each language. We looked at a sample of adult speech in the vicinity of a child around the age of 2;0 in each language. Due to the nature of our recordings, all of which have lots of input speech from other children (siblings, cousins, neighbors, etc.), we agreed to count children over ten years old as adults for the purpose of analyzing the input speech. These samples are approximately the same duration with the exception of Q'anjob'al. Table 4 provides background information on each sample.

Table 4. Samples of Mayan Input Speech

\begin{tabular}{lcccc}
\hline & Child's Age & No. of speakers & Hours Taped & $\begin{array}{c}\text { No. of verbal } \\
\text { utterances }\end{array}$ \\
\hline Yukatek & $2 ; 0$ & 3 & $\sim 4$ & 245 \\
Tzeltal & $1 ; 10-2 ; 10$ & 2 & $\sim 6$ & $\sim 256$ \\
Tzotzil & $1 ; 9$ & 1 & $\sim 4$ & $\sim 186$ \\
Q'anjob'al & $2 ; 3$ & 1 & $\sim 1$ & 296 \\
K'iche' & $2 ; 1$ & 5 & 5 & 807 \\
\hline
\end{tabular}

It is worth noting that even when we tried to find samples that were similar across the languages, some variables were beyond our control. One striking difference concerns the number of speakers who were present during the 
recording sessions. The speech of any given adult was restricted by the number and social status of other speakers who were present at each recording session.

\section{Mayan Children's Early Verb Forms}

Since verbs in the adult Mayan languages have similar inflectional templates it is not clear what factors determine the form of children's early verb productions. We provide examples of the children's early verb forms in (10). We highlight the verb root in each example in italics. The examples in (10a) are all cases where the children produced the verb root minus obligatory inflections for aspect, agreement and status. Adult Mayan speakers frequently produce sentences that only contain a verb, but the adult verbs contain the inflections for subject and object as well as for aspect and status. The children's productions in (10a) lack these obligatory inflectional features. The examples in (10b) illustrate another common verb form for children - the use of the verb root with the status suffix. The status suffix is the most semantically complex affix in the Mayan languages, and yet we find abundant evidence of its early appearance in children's speech (Brown 1998; de León 1999b; Mateo 2005; Pfeiler 2003; Pye 1983). The remaining examples in (10c and d) illustrate more idiosyncratic productions which have a more irregular distribution across the Mayan languages. The applicative suffixes shown in (10d) frequently appears in Tzeltal, Tzotzil and Yukatek child and adult speech, while it is infrequent in K'iche' and absent in Q'anjob'al (Pye 2007).

(10) Mayan Children's Early Verb Forms

a. Bare Root

$\begin{array}{ll}\text { Yukatek } & \text { (Pfeiler 2003) } \\ \text { pax 'play/music' } & \text { (SAN 1;9) } \\ \text { Tzeltal } & \text { (Brown 1997) } \\ \text { muk 'cover' } & \text { (MIK 1;10) } \\ \text { Tzotzil } & \text { (de León 1999a) } \\ \text { k'an 'want' } & \text { (MAL 1;5) } \\ \text { Q'anjob'al } & \text { (Mateo 2005) } \\ \text { tantu 'take care' } & \text { (B 2;7) } \\ \text { K'iche' } & \text { (Pye 1983) } \\ \text { loq' ech wa' 'buy ours then' } & \text { (CHA 2;9) }\end{array}$


b. Root + Status

Yukatek

bin-ih 'go-STA ${ }_{\mathrm{IV}-\mathrm{coM}}$ '

(Pfeiler 2003)

Tzeltal

(SAN 1;9)

poch'-em 'peel-STA INTR-PERF'

(Brown 1997)

Tzotzil

(XAN 2;1)

jam-o 'open(it)-STA TR-IMP'

(de León 1999b)

Q'anjob'al

(MAL 1;1)

man-a' 'buy-STA TV-IMP'

(Mateo 2005)

K'iche'

(B 2;7)

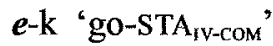

(Pye 1983)

(TIY 2;1)

c. Root+Applicative

Yukatek

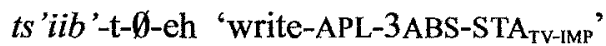

Tzotzil

$a k^{\prime}-\mathrm{b}-\emptyset$-o 'give-APL-3ABS-STA ${ }_{\text {TV-IMP' }}$,

d. Ergative + Root

Q'anjob'al

ko-ten aj '4ERG-touch up'

Figure 1 provides quantitative data on the frequency of bare verb roots in our child data. In this figure, 'root' indicates the pattern illustrated in (10a). We analyzed the productions of transitive (TV) and intransitive (IV) verbs separately in each language since these verb types have different affixes, which affected the rate of bare root production across the languages.

Figure 1 shows large differences between the languages in the proportion of bare verb roots the children produce. Bare verb roots are the most frequent form produced by Tzeltal and Tzotzil children, while K'iche' and Yukatekan children produce both bare roots and root-suffix combinations. Q'anjob'al children display an intermediate position. They produce a mix of root plus status forms for intransitive verbs, but concentrate on verb roots alone for transitive verbs. In fact, Figure 1 shows an interesting difference in the frequency in the verb roots of the children's transitive and intransitive verbs across these five Mayan languages. In all except Q'anjob'al, the children produce more bare roots for intransitive verbs than for transitive verbs. The children also produce more root plus status combinations for transitive verbs than for intransitive verbs. We will show that 


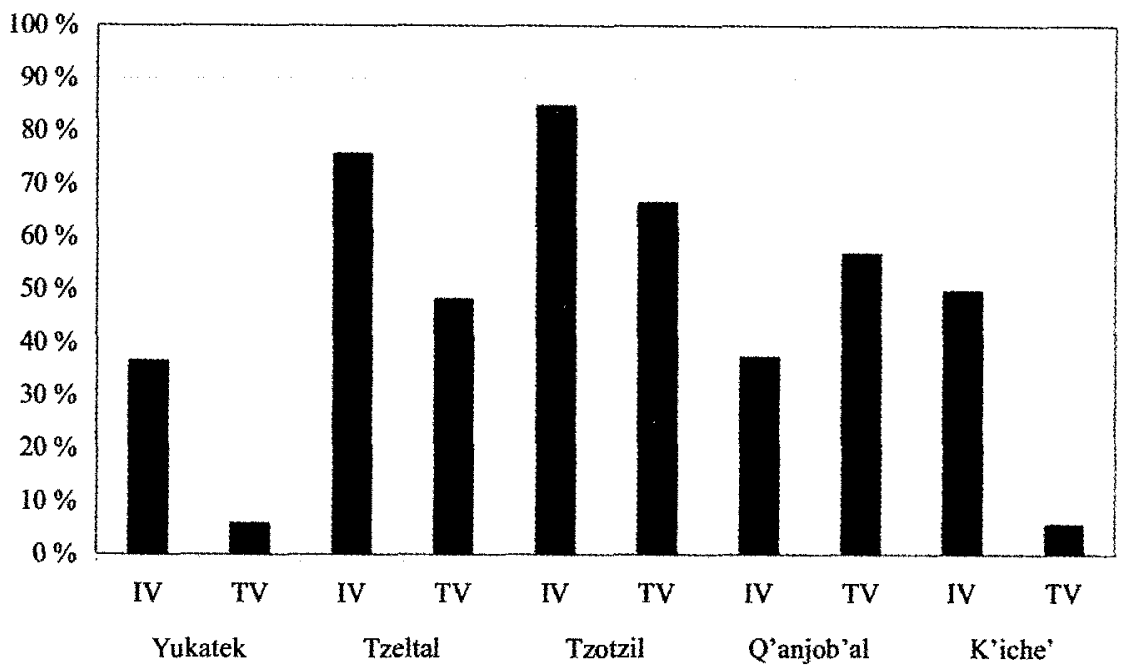

Figure 1. Percentage of Bare Verb Roots in Mayan Children's Speech

this variation provides further insight into the factors that affect children's use of bare verb roots.

In the next section, we test the left edge factors that we think might influence the children's use of bare verb roots.

\section{Testing Left Edge Factors}

An obvious hypothesis is that variation in the linguistic structure of the adult languages dictates the forms of children's verbs. One possibility is that Mayan children are more likely to produce bare verb roots if adults frequently produce verbs without prefixes. If the left word edge is a significant factor in the children's use of bare verb roots, we predict a positive correlation between the frequency of roots at the left edge of verbs in the input and the children's production of verb roots. The input frequencies of verb roots occurring at the left word edge of the verb stem are shown in Figure 2.

We used the Spearman rank order correlation to compare the rank orders of the children and adults (Siegel 1956). This comparison reveals factors that work in common across the five languages, but does not show whether a factor has a stronger effect within the individual languages. We compare the frequency of left word edge verb roots in the input with the children's production of bare verb roots in (11). This comparison is not 


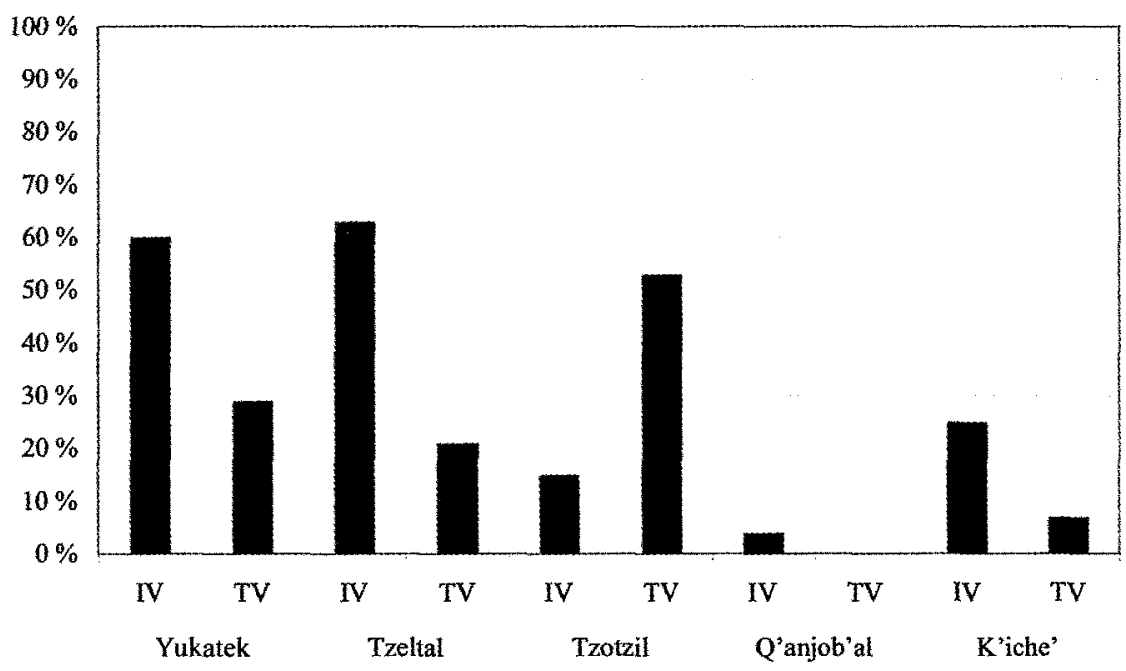

Figure 2. Frequency of Left Word Edge Verb Roots in Child Directed Speech

significant $(\mathrm{r}=0.139 \mathrm{~ns})$. We conclude that the frequency at which Mayan children produce bare verb roots is not tied to the frequency with which verb roots appear at the left edge of the verb in the input.

(11) Comparison of Children's Bare Verbs and Input Frequency of Left Word Edge Roots

Child Frequency of

Bare Verb Roots

1 Tzotzil IV

2 Tzeltal IV

3 Tzotzil TV

4 Q'anjob'al TV

5 K'iche' IV

6 Tzeltal TV

7 Q'anjob'al IV

8 Yukatek IV

9 Yukatek TV

10 K'iche' TV
Input Frequency of

Left Word Edge Roots

1 Tzeltal IV

2 Yukatek IV

3 Tzotzil TV

4 Yukatek TV

5 K'iche' IV

6 Tzeltal TV

7 Tzotzil IV

8 K'iche' TV

9 Q'anjob'al IV

10 Q'anjob'al TV 


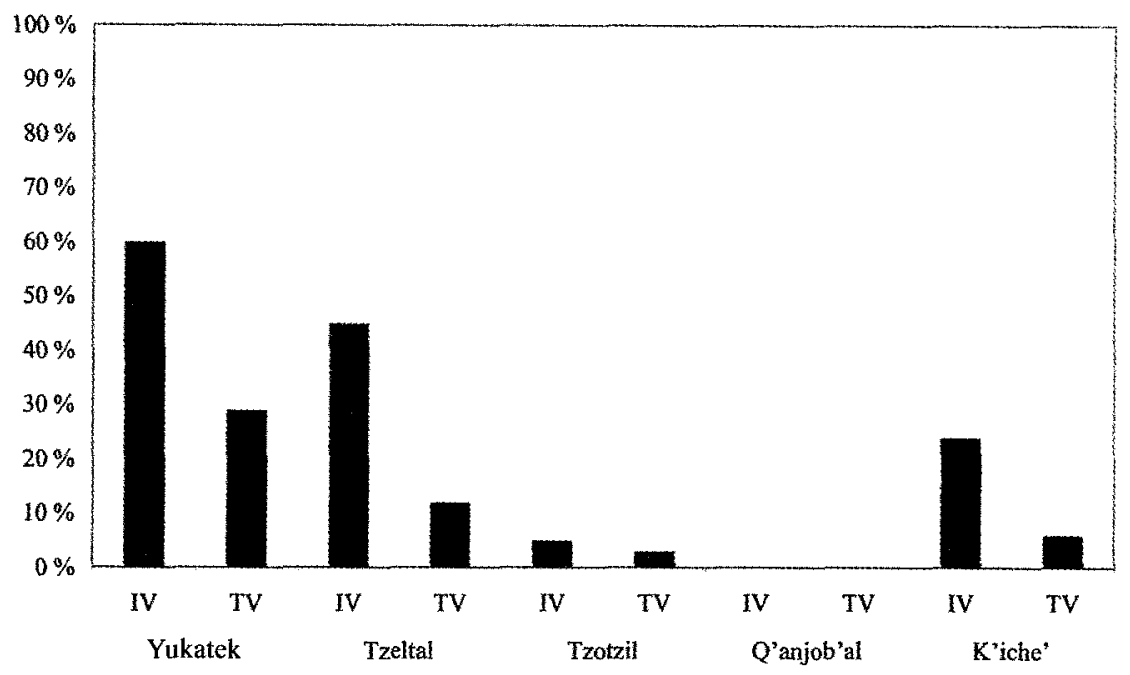

Figure 3. Frequency of Sentence-Initial Verb Roots in Input Speech

\section{Sentence-Initial Position}

We also analyzed the frequency with which the speakers produced verb roots in sentence-initial position in their child directed speech. Verbs commonly occur at the beginnings of sentences in all Mayan languages, so Mayan children might be drawn to the extraction of verbs and verb roots by the frequency of verb-initial sentences in their input. Figure 3 shows the input frequencies at which verb roots appear in sentence initial position in the five languages.

We compare these results with the children's production of verb roots in (12). This comparison also turns out to be non-significant $(r=-0.219 n s)$.

(12) Comparison of Children's and Input Frequency Rank Order for Sentence-Initial Roots

Child Frequency of Bare Verb Roots

1 Tzotzil IV

2 Tzeltal IV

3 Tzotzil TV

4 Q'anjob'al TV
Input Frequency of

Left Sentence Edge Roots

1 Yukatek IV

2 Tzeltal IV

3 Yukatek TV

4 K'iche' IV 

5 K'iche' IV
5 Tzeltal TV
6 Tzeltal TV
7 Q'anjob'al IV
6 K'iche' TV
8 Yukatek IV
7 Tzotzil IV
9 Yukatek TV
8 Tzotzil TV
10 K'iche' TV
9.5 Q'anjob'al IV
9.5 Q'anjob'al TV

\section{Imperatives}

In addition to word and sentence edges, we explored the possibility that the number of imperative verb forms in the input might affect the children's production of verb roots. Our thinking is that positive imperative verb forms are less inflected than verb forms in other aspects and modalities. In all the languages except $K$ 'iche' the positive imperatives lack prefixes for modality and subject agreement. Imperatives in all Mayan languages have a status suffix that should help children to isolate the verb and the verb root. We provide examples of imperative verb forms in (13). The frequency of positive imperatives as a percentage of verbal utterance in input speech is shown in Figure 4.

(13) Examples of Mayan Imperative Verb Forms

Tzeltal

jajch-an

get_up-STA $\mathrm{INTR}-I M P$

Get up!

Tzotzil

lik-an

get_up-STA $\mathrm{INTR}_{\mathrm{IMP}}$

Get up!

Yukatek

liik'-en

get_up-STA $\mathrm{A}_{\mathrm{INTR}-\mathrm{IMP}}$

Get up!

K'iche'

ch-at-pakal-oq

IMP-2ABS-get_up-STA INTR-IMP

Get up! 


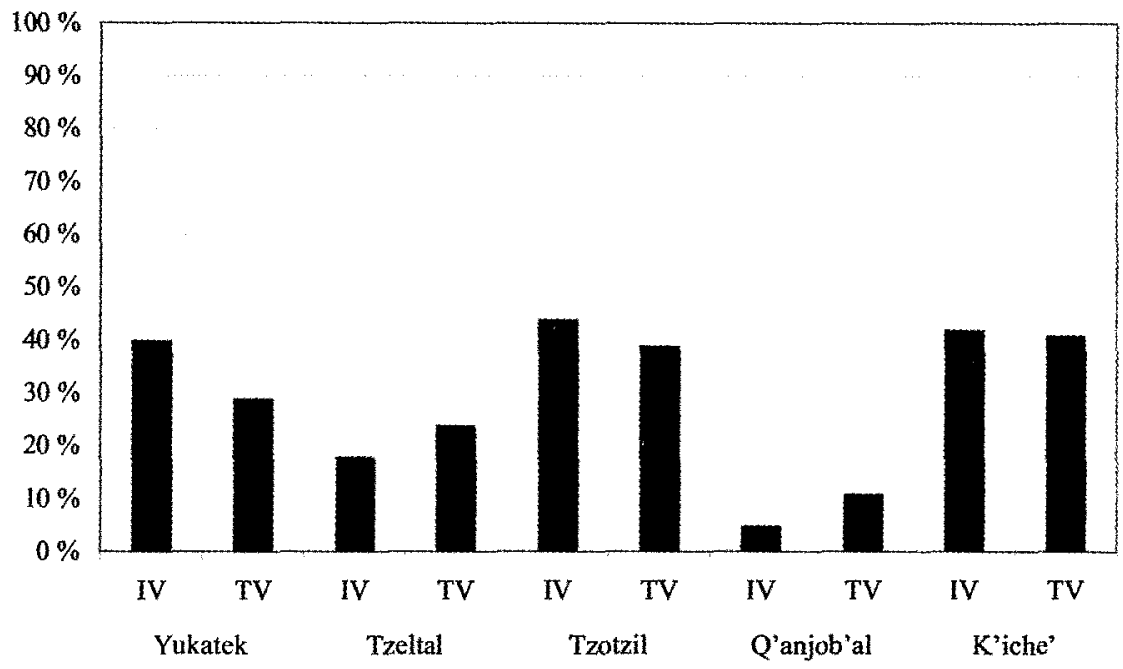

Figure 4. Frequency of Positive Imperatives in Input Speech

We compare the frequency of imperatives in the input with the children's use of bare verb roots in (14). The correlation is not significant $(r=0.042$ ns). We conclude that the number of imperatives in the input is not responsible for the number of bare verb roots we find in the children's production.

(14) Comparison of Positive Imperatives in the Input and Children's Verb Root Production

Child Frequency of Bare Verb Roots

1 Tzotzil IV

2 Tzeltal IV

3 Tzotzil TV

4 Q'anjob'al TV

5 K'iche' IV

6 Tzeltal TV

7 Q'anjob'al IV

8 Yukatek IV

9 Yukatek TV

10 K'iche' TV
Input Frequency of

Positive Imperatives

1 Tzotzil IV

2 K'iche' IV

3 K'iche' TV

4 Yukatek IV

5 Tzotzil TV

6 Yukatek TV

7 Tzeltal TV

8 Tzeltal IV

9 Q'anjob'al TV

10 Q'anjob'al IV

We have tested three left edge factors in the input that might influence the Mayan children's production of bare verb roots: 1 . the frequency at which 
the root occurs at the left edge of the verb, 2. the number of times the root occurs at the beginning of a sentence, and 3 . the number of positive imperatives in the input. None of these factors correlates with the children's production of bare verb roots; hence, we conclude that the children ignored the left edges of verbs and sentences in extracting verb roots. In the next section, we test the effect of right edge factors on the children's production of bare verb roots.

\section{Testing Right Edge Factors}

Another possibility is that Mayan children are more likely to produce bare verb roots if adults frequently produce verbs without suffixes. In other words, the frequent occurrence of verb roots at the right edge of the verb stem will increase the likelihood of children producing just the verb root. If the right word edge is a significant factor in the children's use of bare verb roots, we predict a positive correlation between the frequency of roots at the right word edge in the adult input and the children's production of bare verb roots. The input frequencies of verb roots occurring at the right edge of the verb word in our data are shown in Figure 5.

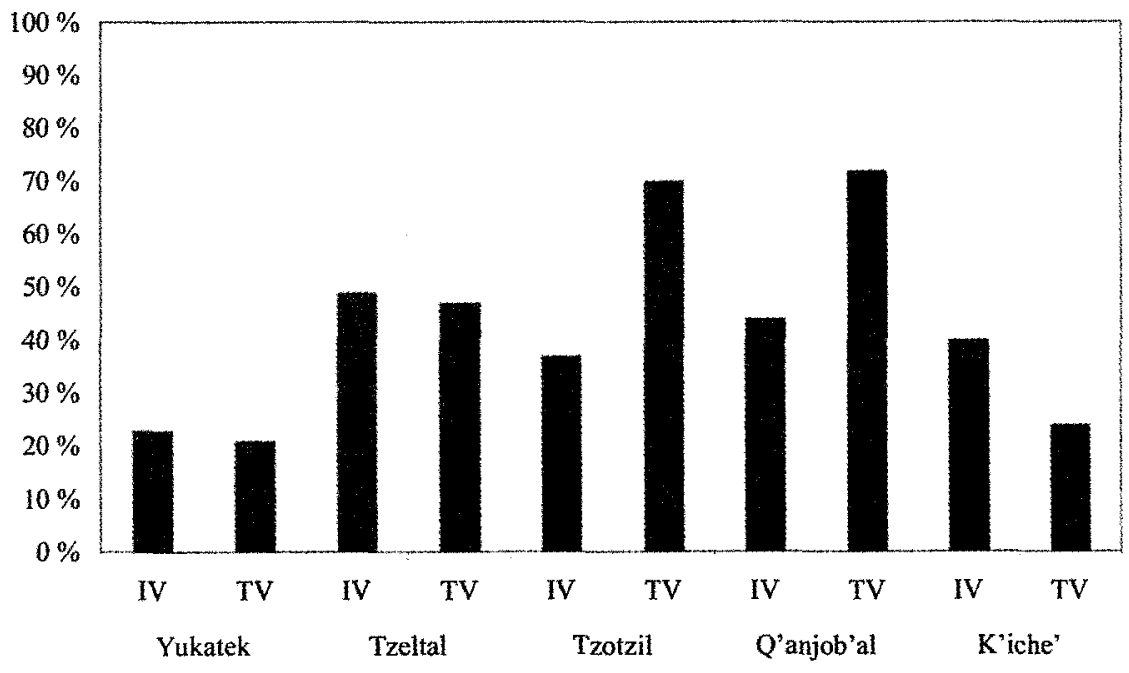

Figure 5. Frequency of Right Word Edge Verb Roots in the Input 
We next compared the frequency at which verb roots in the input were produced at the right word edge in Figure 5 with the children's production of bare verb roots presented in Figure 1. Recall that Figure 1 shows that bare verb roots are the most frequent form produced by the Tzeltal and Tzotzil children, while the K'iche' and Yukatekan children produce both bare roots and root-suffix combinations. If the frequency of adult verbs with roots at the right word edge influences the form of the children's verbs we should find a positive correlation between these two measures. The frequency rank orders for the children's production of bare verb roots and adult verbs with roots at the right word edge are shown in (15).

(15) Comparison of Children's Bare Verbs and Adult Frequency of Right Word Edge Roots

$\begin{array}{ll}\text { Child Frequency of } \\ \text { Bare Verb Roots } \\ 1 & \text { Tzotzil IV } \\ 2 & \text { Tzeltal IV } \\ 3 & \text { Tzotzil TV } \\ 4 & \text { Q'anjob'al TV } \\ 5 & \text { K'iche' IV } \\ 6 & \text { Tzeltal TV } \\ 7 & \text { Q'anjob'al IV } \\ 8 & \text { Yukatek IV } \\ 9 & \text { Yukatek TV } \\ 10 & \text { K'iche' TV }\end{array}$

Adult Frequency of Right Word Edge Roots

1 Q'anjob'al TV

2 Tzotzil TV

3 Tzeltal IV

4 Tzeltal TV

5 Q'anjob'al IV

6 K'iche' IV

7 Tzotzil IV

8 K'iche' TV

9 Yukatek IV

10 Yukatek TV

This comparison reveals a significant positive correlation between the frequency of verb roots occurring at the right word edge in input speech and the children's production of bare verb roots $(r=.624 \mathrm{p}=.05)$. The verb forms that adult Mayan speakers produce influence the frequency at which children produce bare verb roots. Even though these languages share a common inflectional template for verbs, small differences in the adult inflectional paradigms lead to significant differences in the verb forms that children produce.

The same comparison can be made between the children's production of verb roots and the frequency of verb roots at the right sentence edge in adult speech. As we stated previously, only Tzeltal and Tzotzil, as shown in the examples (7), place the verb root at the right edge of the sentence (when 
the verb occurs at the end of the sentence). Yukatek, Q'anjob'al and $K$ 'iche' have obligatory status suffixes that come between the verb root and the right edge of the sentence. Figure 6 shows the frequency of verb roots at the right edge of the sentence in our samples of input speech.

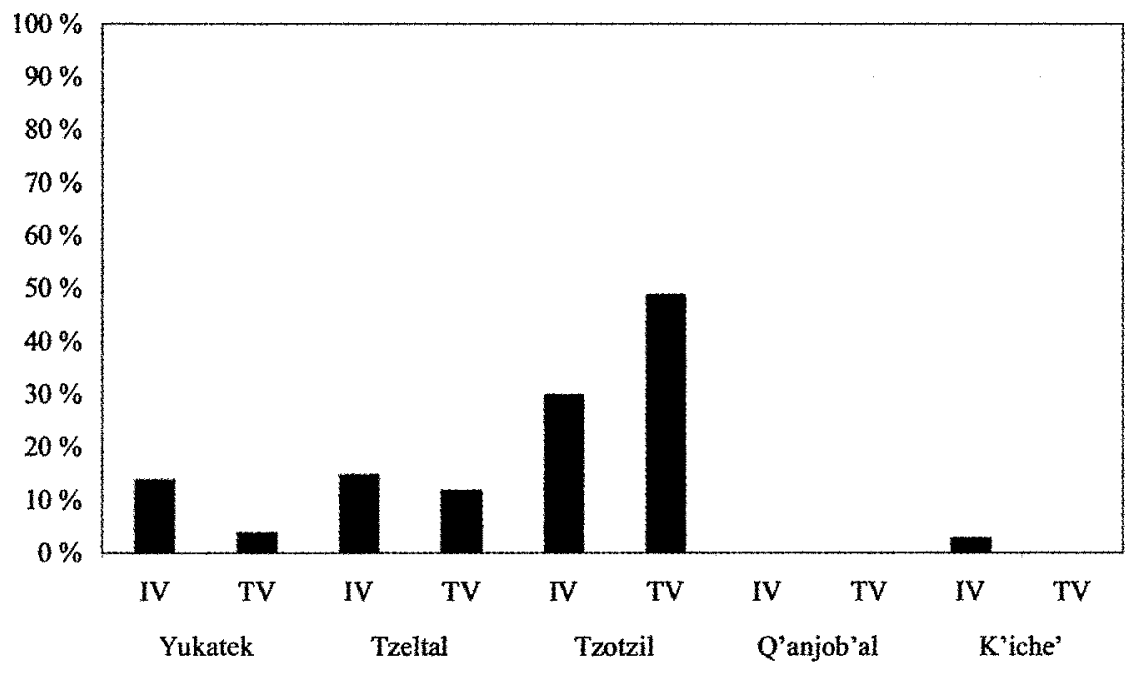

Figure 6. Frequency of Sentence-Final Verb Roots in Child Directed Speech

Figure 6 confirms our impression that adults produce verb roots at the end of sentences most frequently in Tzeltal and Tzotzil. Although verb roots frequently occur at the end of the verb stem in Q'anjob'al, they never appear at the ends of sentences. If the input frequency of verbs with roots at the right sentence edge influences the form of the children's verbs we should find a correlation between these two measures. We compare the frequency of right sentence edge verb roots in the input speech with the frequency of verb roots in the children's productions in (16). This comparison is also significant $(r=0.596 ; p=.05)$. Our comparisons show that the children's production of bare verb roots is significantly correlated with the frequency with which the verb root appears at the right word edge as well as the right sentence edge in the input. 
(16) Comparison of Children's Bare Verbs and Input Frequency of Right Sentence Edge Roots

Child Frequency of

Bare Verb Roots

1 Tzotzil IV

2 Tzeltal IV

3 Tzotzil TV

4 Q'anjob'al TV

5 K'iche' IV

6 Tzeltal TV

7 Q'anjob'al IV

8 Yukatek IV

9 Yukatek TV

10 K'iche' TV
Input Frequency of

Right Sentence Edge Roots

1 Tzotzil TV

2 Tzotzil IV

3 Tzeltal IV

4 Yukatek IV

5 Tzeltal TV

6 Yukatek TV

7 K'iche' IV

9 K'iche' TV

9 Q'anjob'al IV

9 Q'anjob'al TV

Tzeltal and Tzotzil lack status suffixes for the plain aspects, a fact which increases the frequency with which the verb roots appear in sentence-final position in these languages. Yukatek, Q'anjob'al and K'iche', on the other hand, have status suffixes which intrude between the verb roots and the right sentence edge. Despite this structural difference, our result shows the variation in the children's use of bare verb roots correlates with the proportion of verb roots at the right edge in the input. Tzeltal and Tzotzil merely lie at one extreme of a continuum.

\section{Verb Derivation}

We also explored the hypothesis that a high proportion of derived verb forms in adult speech will have a negative correlation with the children's production of bare verb roots. It seems reasonable to suppose that, since verb derivation is expressed through suffixes in Mayan languages, the number of derived verbs in the input should interfere with children's use of bare verb roots. Another possibility is that the more derived verbs children find in the input the more likely they are to produce a form that consists of a verb root and a derivational suffix. We provide examples of derived verbs in (17). (Roots are italicized; derivational suffixes are underlined.) These examples illustrate various derivational processes that occur in Mayan languages. All of the languages have a form of the ProtoMayan causative suf- 
fix similar to that found in Yukatek. Tzeltal and Tzotzil have a productive applicative suffix that is not used as frequently in the other languages. Q'anjob'al and K'iche' maintain a reflex of the PM status suffix that distinguishes a class of derived transitive verbs. The frequency of each of these derivational processes differs dramatically from language to language. The proportion of nonderived verbs in adult speech is shown in Figure 7.

(17) Examples of Derived Verbs

Yukatek - Causative

$l i ' i(k)$-s $-\mathrm{eh}$

get_up-CAUS-STA

'Get someone up!'

Tzeltal - Applicative

$\mathrm{k}-a k^{\prime}$-oj-be-at

1ERG-give-PERF-APPL-2ABS

'I have given it to you'
Tzotzil - Applicative

y-ak'-oj-be-on

3ERG-give-PERF-APPL-1 ABS

'He/she gave it to me.'

K'iche' - 'Derived' Verbs

k-0-inw- $a a-\mathrm{j}$

INC-3ABS-1ERG-want-STA TV-DER $_{\text {- }}$

'I want it'

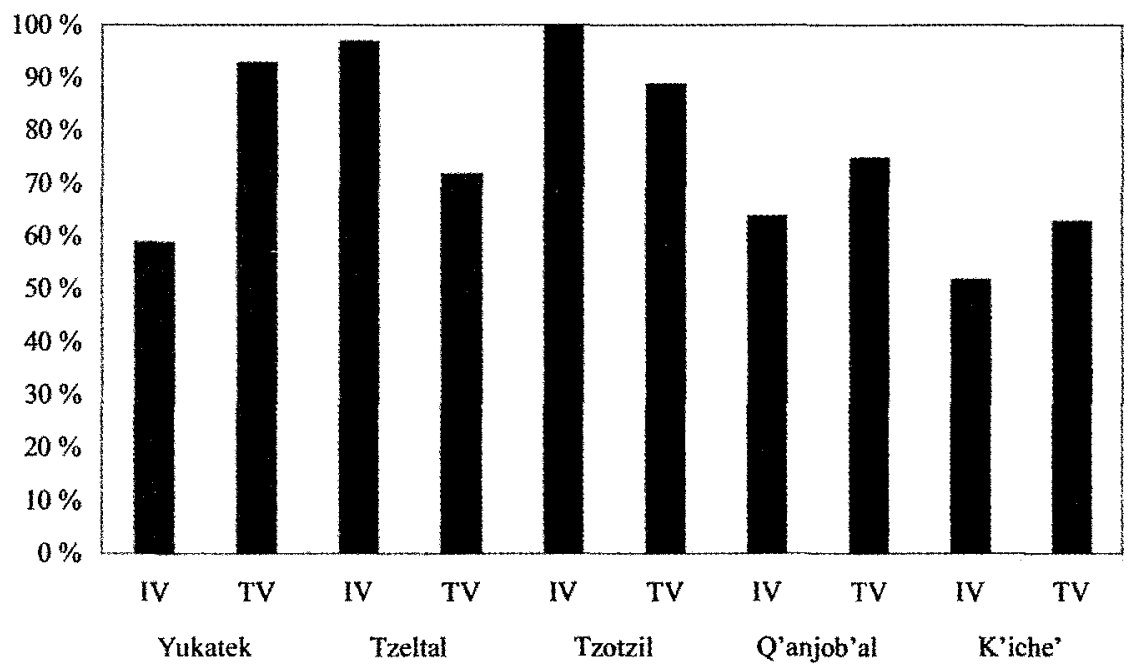

Figure 7. Proportion of Nonderived Verbs in Input Speech

We compare the proportion of nonderived verbs in the input with the children's production of bare verb roots in (18). This time we find a significant 
correlation between the proportion of nonderived verbs in adult speech and the children's production of bare verb roots $(r=0.588 ; p=.05)$. This result supports our earlier finding that the children are sensitive to the right word edge. Both inflection and derivation affect the right word edge and influence the children's production of verb roots.

(18) Comparison of Adult Nonderived Verbs and Children's Bare Verb Root Production

\begin{tabular}{llll} 
Child Frequency of & \multicolumn{2}{c}{ Input Frequency of } \\
Bare Verb Roots & \multicolumn{2}{c}{ Nonderived Verbs } \\
1 Tzotzil IV & 1 & Tzotzil IV \\
2 & Tzeltal IV & 2 & Tzeltal IV \\
3 & Tzotzil TV & 3 & Yukatek TV \\
4 & Q'anjob'al TV & 4 & Tzotzil TV \\
5 & K'iche' IV & 5 & Q'anjob'al TV \\
6 & Tzeltal TV & 6 & Tzeltal TV \\
7 & Q'anjob'al IV & 7 & Q'anjob'al IV \\
8 & Yukatek IV & 8 & K'iche' TV \\
9 & Yukatek TV & 9 & Yukatek IV \\
10 & K'iche'TV & 10 & K'iche' IV
\end{tabular}

\section{Status Suffixes}

There is also a common set of verb inflections we can examine for its effect on childrens bare root production - the status suffixes. The status suffix appears just after the verb root and any derivation (see the Mayan verb template in (2) above). The status suffix also lies at the heart of the propositional structure since the suffix expresses aspect, modality and sentence status. We can press the status suffix into service as an independent test of the right edge effect. We expect children to produce more bare roots to the extent that the input lacks overt status suffixes.

Figure 8 shows the frequency of status suffixes in the input. We tested whether the use of status suffixes in the input was inversely related to the children's production of bare verb roots, and this is precisely what we find (19). This comparison produced a significant negative correlation $(r=$ $-0.806 ; p=.01)$. It also turns out that the use of status suffixes in the input positively correlates with the children's use of status suffixes $(r=0.894 ; p$ $=.01)$, as presented in $(20)$. 


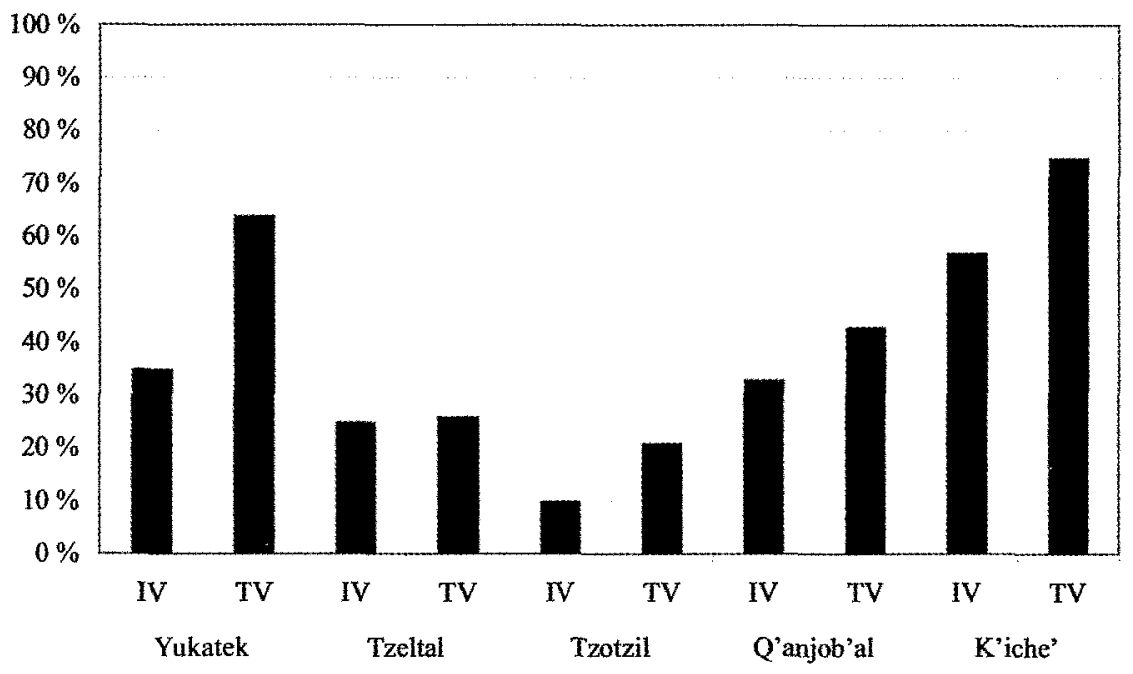

Figure 8. Status Suffix Frequency in the Input

(19) Comparison of Child and Input Status Suffix Usage

Children

1 Yukatek TV

2 K'iche' TV

3 K'iche' IV

4 Yukatek IV

5 Q'anjob'al TV

6 Tzotzil TV

7 Q'anjob'al IV

8 Tzeltal TV

9.5 Tzeltal IV

9.5 Tzotzil IV
Input

1 K'iche' TV

2 Yukatek TV

3 K'iche' IV

4 Q'anjob'al TV

5 Yukatek IV

6 Q'anjob'al IV

7 Tzeltal TV

8 Tzeltal IV

9 Tzotzil TV

10 Tzotzil IV

(20) Comparison of Input Status Suffix Usage with the Children's Production of Bare Verb Roots

Child Frequency of Bare Verb Roots

1 Tzotzil IV

2 Tzeltal IV

3 Tzotzil TV
Input Frequency of

Status Suffixes

1 K'iche' TV

2 Yukatek TV

3 K'iche' IV 


$\begin{array}{llll}4 & \text { Q'anjob'al TV } & 4 & \text { Q'anjob'al TV } \\ 5 & \text { K'iche' IV } & 5 & \text { Yukatek IV } \\ 6 & \text { Tzeltal TV } & 6 & \text { Q'anjob'al IV } \\ 7 & \text { Q'anjob'al IV } & 7 & \text { Tzeltal TV } \\ 8 & \text { Yukatek IV } & 8 & \text { Tzeltal IV } \\ 9 & \text { Yukatek TV } & 9 & \text { Tzotzil TV } \\ 10 & \text { K'iche'TV } & 10 & \text { Tzotzil IV }\end{array}$

\section{Verb Root Structure}

The final factor we explored was the shape of the verb root. Tzeltal and Tzotzil contain a high proportion of CVC verb roots, while K'iche' verb roots display more variation. Examples of two different types of $\mathrm{K}$ 'iche' verb roots are shown in (21). Figure 9 shows the proportion of CVC verb roots in the Mayan input.

(21) Examples of K'iche' Verb Root Structure

k-0-pet-ik

INC-3ABS-come-STA $\mathrm{IV}_{\mathrm{V}-\mathrm{INC}}$

$\mathrm{He} / \mathrm{She}$ is coming. k-0-xojow-ik

INC-3ABS-dance-STA IV-INC $_{\text {- }}$

$\mathrm{He} / \mathrm{She}$ is dancing.

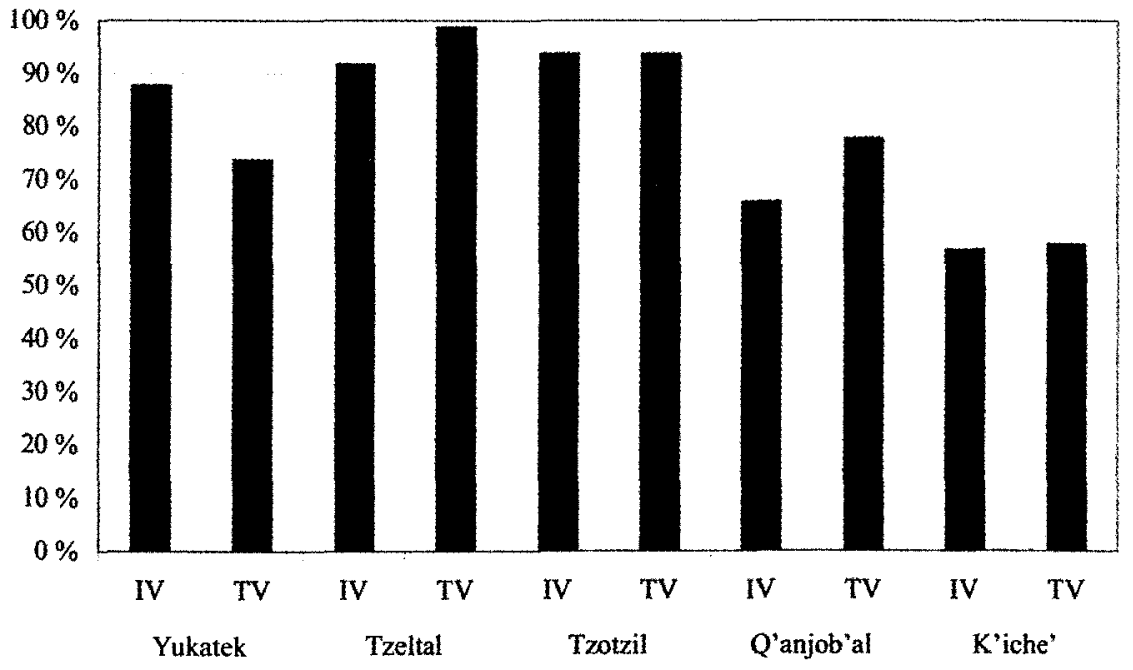

Figure 9. Frequency of CVC Verb Roots in the Input 
We compare the frequency of CVC Verb Roots in the input with the children's production of bare verb roots in (22). This factor also turns out not to be significant in predicting the children's use of bare verb roots $(\mathrm{r}=$ $0.541 \mathrm{~ns})$.

(22) Comparison of Input CVC Verb Root Frquency and Children's Verb Root Production

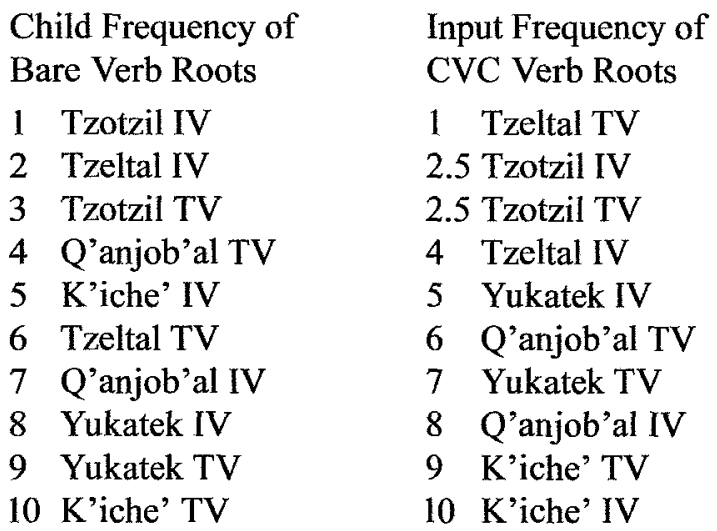

In sum, we tested five right edge factors in this section: 1 . the frequency at which verb roots are produced at the right lexical edge, 2 . the frequency at which verb roots occur at the ends of sentences, 3 . the frequency of derivational suffixes, 4 . the frequency of status suffixes, 5. the frequency of CVC verb roots. We found that the frequency at which verb roots occur at the right edge of the verb and sentence in the input was positively correlated with the children's production of bare verb roots, while the frequency of derivation and the status suffixes in the input was negatively correlated with the children's production of bare verb roots.

We conclude that the frequency with which adults produce verb roots at the right edge of words and sentences influences the frequency at which children produce bare verb roots in their productions, but the left edge does not. The position that the verb usually occupies in the sentence (initial position) does not affect children's ability to extract the verb root, nor does the degree to which the verb carries inflectional prefixes. The present analysis shows the predictive power of right edge factors even without accounting for other possible factors. ${ }^{4}$ We can add that this right edge influence is general across the five languages in our study, despite significant differences in their inflectional paradigms. 


\section{Discussion}

In the Mayan languages, children must determine where the division between root and affix occurs. This necessity pits the basic semantic kernel against inflectional elements such as person and modality. If we just looked at the children's productions in Tzeltal and Tzotzil, we would think the children were drawn to the semantic kernels of verbs. However, the children's productions in Yukatek, Q'anjob'al and K'iche' highlight the degree to which the structure of the input in Tzetal and Tzotzil favors the extraction of verb roots. The structure of the input language, not the semantic kernal, influences the form of children's verbs.

One of the more interesting variables across our languages is the degree to which adult speech employs derived verb forms. This is not a variable one normally thinks of when making crosslinguistic comparisons. Most derivations in Mayan languages affect the right edge of the verbal complex and we have shown that derivation in adult speech interferes with the childrens production of bare verb roots. Mayan children will produce derived verbs to the extent that they appear in the input.

We conclude that children produce bare verb roots to the extent that adult speech features verb roots at the right edge of the word and sentence. When derivation and status inflections are added to the right edge, children also incorporate these elements into their early productions. If the children are repeating what they hear in their input, it is natural to ask whether there is any indication that they understand every element of the verb they produce. There are two indications that they do. The first is from children acquiring Yukatek: some go through an early phase in which they extend the transitive status suffix on imperatives to intransitive imperative verbs (Pfeiler 2003). They do not hear these forms in the input, so once phonological development has been eliminated as a source of this error the only other possibility is that two-year old Yukatek children recognize the status suffix as separable from the verb base and extend it to intransitive verbs, good evidence that they have successfully processed the status suffix at some level.

A second indication that Mayan children actively process the status suffixes comes from the alternation between phrase-medial and phrase-final forms of the status suffixes in Yukatek, Q'anjob'al and K'iche'. If the children simply produced the status suffixes as rote memorizations in these languages, we would not expect them to differentiate between these forms. Instead we find they vary their production of the status suffixes by the posi- 
tion of the verb. While it is true that they occasionally overgeneralize the phrase-final forms to phrase-medial contexts, they do not do this constantly (Mateo 2005; Pfeiler 2003; Pye 1983).

Throughout our analysis, we have pursued a surface account of Mayan children's verb forms. We have examined several surface features of verbs in the adult input that might determine the children's initial verb forms. Our findings have major implications for theoretical accounts of language acquisition. Wexler and others have suggested that children alternate between finite and non-finite verb forms in the initial period of language development (Radford 1996; Rizzi 1993/1994; Wexler 1994). These accounts link uninflected forms of children's verbs to limitations in children's syntactic structures. All of these approaches assume that the non-finite verb forms children produce are appropriate in some adult sentence contexts, e.g. following negation. The Mayan children's verb forms summarized in Figure 1 above violate this assumption, suggesting that attempts to state syntactic conditions on the forms of children's early verbs are mistaken.

At first glance, usage-based theories of acquisition (Maratsos \& Chalkley 1980; Tomasello 2003) appear to provide a better account of the Mayan children's early verb forms. These accounts place a great deal of emphasis on the effects of input frequency and semantic complexity. Our findings create some difficulties for these theories as well. Mayan children do not simply produce a copy of the adult verbs. Instead they initially produce only parts of the verb. Frequency alone cannot account for the parts of the verb that the children produce, since we have shown that an asymmetry exists between the left and right edges of the verb. The status suffixes present severe difficulties for theories based on semantic complexity. Mayan children are far more sensitive to features of the right verb edge (derivation, status) than to features of the left verb edge (aspect, agreement). The examples of inflectional overgeneralization we noted above also argue against a simple usage-based model of inflectional acquisition in the Mayan languages.

Mayan children display a remarkable sensitivity to each part of the Mayan verbal complex. The parts of the verbal complex they produce are attuned to the structure of the input which displays considerable variation across the languages. The historically constrained variation in the forms of the verbal complex across our languages allows us to see how a single developmental process unfolds from five different perspectives.

The results we have presented to this point are very preliminary. For the purposes of this presentation we examined the correlation between lan- 
guage features from a single adult and child in each language. Our next task is clearly to add other pairs of speakers to the analysis for each language so that we can better ascertain the variation that exists within the languages as well as across the languages. We are encouraged that the crude statistical analyses we performed on this data were sufficient to reveal common features of the acquisition process across the languages.

Our study represents the first large-scale analysis of acquisition data from related languages. ${ }^{5}$ This unique data set allows analyses that would not be possible with acquisition data from unrelated languages. Inclusion of acquisition data from English and Italian would introduce too many extraneous variables, as both the morphology and syntax of the Indo-European languages differ markedly from the morphology and syntax of the Mayan languages. The restriction to this set of related Mayan languages permits us to analyze the variation in children's verb productions in great detail. We can also exploit evidence from some of the languages to reach conclusions about the acquisition of all the languages. Evidence in some of the languages that Mayan children actively process the status suffixes allows us to conclude that children acquiring all Mayan languages actively process status suffixes. Documenting the acquisition of Q'anjob'al leads to a deeper understanding of the acquisition process in K'iche' and vice versa. Working within a single language it is all too easy to assume that features such as aspect cohere semantically as well as in acquisition. It is only after comparing K'iche' with Tzotzil and Yukatek that we recognized the need to make aspectual distinctions between transitive and intransitive verbs. There were literally a hundred other comparisons that we needed to make as a group in order to produce this analysis. Crosslinguistic comparison of unrelated languages cannot obtain this level of precision.

\section{Notes}

* This paper is a revised version of a presentation we made at the International Association for the Study of Child Language in Berlin in July 2005. The order of authors reflects the fact that the first author took responsibility for writing various drafts. The research is a product of various years of joint collaboration by the authors. We thank Elena Lieven, Dan Slobin, Ann Peters, Richard Weist, Nancy Budwig and Joan Bybee for their comments in that venue. We owe a special thanks to Jürgen Bohnemeyer for his critical reading of a preliminary version of this paper. We accept responsibility for any remaining errors in our analysis. 
The research on Tzotzil was supported by CONACYT Mexico proyecto 42585-H to de León; the research on K'iche' and Q'anjob'al was supported by National Science Foundation grant BCS-0515120 to Pye.

1. K'iche' and Q'anjob'al are the official spellings adopted in Guatemala during the 1980s. All Mayan examples are shown in the practical orthography developed by the Proyecto Linguístico Francisco Marroquín (Kaufman 1976) with a single exception: we use $<^{b}>$ rather than $<7>$ for the glottal stop. The other orthographic symbols have their standard IPA values except: $\langle\mathrm{tz}\rangle=/ \mathrm{ts} /,<\mathrm{ch}\rangle=$

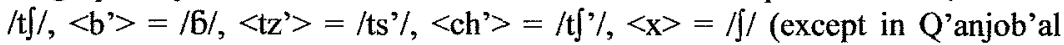
where $\langle\mathrm{x}\rangle=/ \mathrm{s} /),\langle\mathrm{j}\rangle=/ \mathrm{x} /$, and $\otimes=$ high tone. We use the following abbreviations throughout the article:

$\begin{array}{llll}1 & \text { first person singular } & \text { ABS } & \text { absolutive cross-reference } \\ 2 & \text { second person singular } & \text { ERG } & \text { ergative cross-reference } \\ 3 & \text { third person singular } & \text { STA } & \text { status suffix } \\ 4 & \text { first person plural } & \text { V } & \text { vowel } \\ \text { COMPL } & \text { completive aspect } & \text { NEG } & \text { negation } \\ \text { INC } & \text { incompletive aspect } & \text { SM } & \text { sentence medial } \\ \text { PL } & \text { plural } & \text { DIST } & \text { distant } \\ \text { PRF } & \text { perfect } & \text { INTENS intensifier } \\ \text { APPL } & \text { applicative suffix } & \text { PASS } & \text { passive suffix } \\ \text { ANTIP } & \text { antipassive suffix } & \text { POT } & \text { potential } \\ \text { AUX } & \text { auxiliary verb } & \text { SBJV } & \text { subjunctive } \\ \text { IMP } & \text { imperative } & \text { PT } & \text { particle } \\ \text { TR } & \text { transitive verb } & \text { DET } & \text { determiner } \\ \text { INTR } & \text { intransitive verb } & \text { DER } & \text { derived } \\ \text { CLF } & \text { noun classifier } & \text { PROX } & \text { proximate } \\ \text { PROG } & \text { progressive } & \text { CAUS } & \text { causative }\end{array}$

2. The aspectual prefixes coordinate with the Mayan status suffixes discussed below. Mayan languages use the combination of aspectual prefix and status suffix to distinguish between different aspects and moods.

3. The data for Yukatek was collected in Yalcobá, Yucatan, the data for Tzeltal in Majosik', Tenejapa, Chiapas, the Tzotzil data in Nabenchauk, Zinacantán, Chiapas, the data for Q'anjob'al in Santa Eulalia, Guatemala, and the data for $\mathrm{K}$ 'iche' in Zunil, Guatemala.

4. Our analysis neglects stress placement in the languages, which we assume also influences the children's verb forms (Pye 1981). An analysis of the interaction of the right edge factors with stress remains for a future study.

5. Plunkett \& Strömqvist (1992: 540) cite a personal communication from Melissa Bowerman, who discusses the strengths and weaknesses of two approaches to crosslinguistic research. The first approach compares languages that differ considerably from one another. This approach can 'refute gross overgeneralizations of universalist claims', but cannot reveal details of the acquisition process 
'precisely because of the fine-grained nature of the differences between the linguistic systems under investigation.' The second approach compares languages 'that differ only marginally across broad and detailed dimension' (sic). 'Given that two closely related languages share many properties within a given linguistic domain but differ on just one or two dimensions, the causes and ramifications of these differences can be more carefully explored.' The second approach comes close to our application of the comparative method, but does not implement the comparative method's techniques.

\section{References}

Brown, Penelope

1997 Isolating the CVC root in Tzeltal Mayan: a study of children's first verbs. In The Proceedings of the 28th Annual Child Language Research Forum, Eve V. Clark (ed.), 41-52. Stanford, CA: CSLI/University of Chicago Press.

1998 Children's first verbs in Tzeltal: evidence for an early verb category. In Elena Lieven (ed.), Special edition of Linguistics 36(4): 713-53.

de León, Lourdes

1999a Verb roots and caregiver speech in early Tzotzil (Mayan) acquisition. In Cognition, discourse and function, Barbara Fox, Dan Juravsky \& Laura Michaelis (eds.), 99-119. Stanford, CA: CSLI/University of Chicago Press.

1999b Verbs in Tzotzil early syntactic development. International Journal

Kaufman, Terrence of Bilingualism 3(2/3): 219-240.

1976 El proyecto de alfabetos y ortografias para escribir las lenguas mayances. Guatemala: Proyecto Lingüístico Francisco Marroquin \& Ministerio de Educación.

1990 Algunos rasgos estructurales de los idiomas mayances con referencia especial al K'iche'. In Lecturas sobre la Lingüistica Mava, Nora C. England \& Stephen R. Elliott (eds.), 59-114. Guatemala: Centro de Investigaciones Regionales de Mesoamérica.

Kaufman, Terrence S. \& Norman, William M.

1984 An outline of proto-Cholan phonology, morphology, and vocabulary. In Phoneticism in Mayan Hieroglyphic Writing, John S. Justeson \& Lyle Campbell (eds.), 77-166. Albany, NY: Institute for Mesoamerican Studies, State University of New York at Albany.

Maratsos, Michael \& Mary Anne Chalkley

1980 The internal language of children's syntax: the ontogenesis and representation of syntactic categories. In Children's Language, Vol. 2, Keith E. Nelson (ed.). New York: Gardner Press. 
Mateo, Pedro

2005 The Acquisition of Verb Inflection in Q'anjob'al. Unpublished MA thesis, Lawrence, KS: The University of Kansas.

Pfeiler, Barbara

2003 Early acquisition of the verbal complex in Yucatec Maya. In Development of Verb Inflection in First Language Acquisition: A Cross-Linguistic Perspective, Dagmar Bittner, Wolfgang U. Dressler \& Marianne Kilani-Schoch (eds.), 379-399. Berlin/New York: Mouton de Gruyter.

Pfeiler, Barbara \& Enrique Martín-Briceño

1998 La adquisición de los verbos transitivos en el maya yucateco. Función 17-18: 97-120.

Plunkett, Kim \& Sven Strömqvist

1992 The acquisition of Scandinavian languages. In The Crosslinguistic Study of Language Acquisition, Vol. 3, Dan I. Slobin (ed.), 457--556. Hillsdale, NJ: Erlbaum.

Pye, Clifton

1983 Mayan telegraphese: intonational determinants of inflectional development in Quiche' Mayan. Language 59: 583-604.

Ms. The comparative context for Mayan status suffix acquisition. Kansas Working Papers in Linguistics.

2007 The genetic matrix of Mayan three-place predicates. In Bhuvana Narasimhan, Sonja Eisenbeiss \& Penelope Brown (eds.), Special Edition of Linguistics 45(3): 653-681.

Radford, Andrew

1996 Toward a structure-building model of language acquisition. In Generative Perspectives on Language Acquisition, Harold Clahsen (ed.). Amsterdam: John Benjamins.

Rizzi, Luigi

1993/94 Some notes on linguistic theory and language development: the case of root infinitives. Language Acquisition 3: 371-393.

Robertson, John S.

1992 The History of Tense/Aspect/Mood/Voice in the Mayan Verbal Complex. Austin, TX: University of Texas Press.

Siegel, Signey

1956 Nonparametric Statistics for the Behavioral Sciences. New York: McGraw-Hill.

Tomasello, Michael

2003 Constructing a Language: A Usage-Based Theory of Language Acquisition. Cambridge, MA: Harvard University Press.

Wexler, Kenneth

1994 Optional infinitives, head movement and economy of derivation. In Verb Movement, Norbert Hornstein \& David Lightfoot (eds). Cambridge: Cambridge University Press. 